\title{
L'église franciscaine de La Cordelle à Vézelay
}

\section{Denis Cailleaux}

\section{(2) OpenEdition}

\section{Journals}

\section{Édition électronique}

URL : https://journals.openedition.org/cem/3452

DOI : $10.4000 /$ cem.3452

ISSN : 1954-3093

Éditeur

Centre d'études médiévales Saint-Germain d'Auxerre

Édition imprimée

Date de publication : 15 août 2003

ISSN : 1623-5770

\section{Référence électronique}

Denis Cailleaux, « L'église franciscaine de La Cordelle à Vézelay », Bulletin du centre d'études médiévales d'Auxerre | BUCEMA [En ligne], 7 | 2003, mis en ligne le 22 novembre 2007, consulté le 22 septembre 2022. URL : http://journals.openedition.org/cem/3452 ; DOI : https://doi.org/10.4000/cem.3452

Ce document a été généré automatiquement le 22 septembre 2022.

\section{(c) (i) (2)(2)}

Creative Commons - Attribution - Pas d'Utilisation Commerciale - Partage dans les Mêmes Conditions 4.0 International - CC BY-NC-SA 4.0

https://creativecommons.org/licenses/by-nc-sa/4.0/ 


\title{
L'église franciscaine de La Cordelle à Vézelay
}

\author{
Denis Cailleaux
}

1 La maison des Frères mineurs de Vézelay passe pour être la plus ancienne des implantations françaises de l'ordre franciscain. Selon une tradition établie depuis longtemps, c'est en 1217 que deux disciples de François d'Assise - Frère Pacifique et son compagnon Frère Louis - auraient jeté les bases de cette fondation. L'établissement franciscain, appelé La Cordelle, était situé hors des murailles de la ville, au nord, près de la porte Sainte-Croix, sur le chemin menant à Asquin. Les Mineurs, ou Cordeliers, occupèrent le couvent du XIII ${ }^{e}$ siècle à la Révolution française. Vendue comme Bien national en 1791, la Cordelle fut transformée en carrière de pierre au début du XIX ${ }^{\mathrm{e}}$ siècle, puis elle devint l'annexe d'une exploitation agricole. Les bâtiments furent alors en grande partie détruits et ceux qui subsistaient furent transformés pour accueillir charrettes et troupeaux. Entré dans le patrimoine de la famille des comtes de Chastellux en 1824, l'ancien couvent retrouva sa vocation religieuse en 1949, lorsque les franciscains y établirent un ermitage. Les Frères mineurs occupent toujours la maison qui abrite une petite communauté permanente et accueille des frères désireux de faire retraite.

2 L'histoire de la Cordelle de Vézelay est assez bien connue, en comparaison à celle d'autres maisons franciscaines, grâce à un petit fonds de pièces anciennes déposé aux Archives départementales de l'Yonne, auxquelles s'ajoutent divers documents conservés dans des fonds publiques ou privés. Cette documentation a été exploitée par les Frères Ambroise Négrel et Damien Vorreux, qui ont retracé l'histoire du couvent vézelien dans un texte resté malheureusement confidentiel ${ }^{1}$.

3 Les informations relatives aux bâtiments sont cependant peu nombreuses et lorsqu'elles existent, elles se rapportent essentiellement aux travaux réalisés à l'Époque moderne. L'aspect du couvent à l'époque médiévale reste inconnu et les éléments architecturaux actuellement visibles datent essentiellement des XVII ${ }^{\mathrm{e}}$ et XVIII ${ }^{\mathrm{e}}$ siècles. Cependant, il est possible que les rares vestiges conservés de l'église franciscaine appartiennent à l'établissement médiéval ou, du-moins, en reprennent les fondements. 
4 Actuellement, il ne reste de l'ancienne église conventuelle que son emplacement qui se présente comme une aire ouverte gazonnée limitée par des murs de pierres plates. On y accède par un porche couvert, placé en avant de l'accès ouest, qui date du XVII ${ }^{\mathrm{e}}$ siècle. Le porche franchi, on pénètre dans l'espace de l'ancienne nef, bordé à main gauche par la chapelle romane Sainte-Croix, toujours conservée. L'église mesurait environ $25 \mathrm{~m}$ de long et $7 \mathrm{~m}$ de large. Elle se terminait, à l'est, par un chevet à trois pans. Le muret de clôture actuel conserve cette forme, mais il semble qu'il ait été rebâti il y a quelques décennies par un religieux franciscain. En effet, dans la seconde moitié du XIX siècle, aucun vestige significatif n'était alors conservé lorsque Max Quantin rédigea une notice sur la Cordelle pour son Répertoire archéologique ${ }^{2}$. On notera que Quantin a interprété les vestiges de Sainte-Croix - qu'il désigne sous l'ancien nom de chapelle Saint-Fiacre comme les restes d'un transept. À la même époque, Victor Petit a publié une brève notice sur la Cordelle, sans signaler d'autres vestiges d'église que ceux de Sainte-Croix ${ }^{3}$.

Si aucune trace de l'église franciscaine de Vézelay n'était visible au XIX ${ }^{e}$ siècle, on peut cependant être assuré que son emplacement correspond effectivement à l'espace délimité par les murets actuels, au nord de la chapelle Sainte-Croix. Deux plans du XVIII ${ }^{e}$ siècle permettent en effet de connaître la disposition générale des édifices à cette époque et confirment la situation de la chapelle. La question qui se pose à nous est celle de l'ancienneté de ce sanctuaire. S'agissait-il de la construction primitive ou d'une reconstruction postérieure au XIII ${ }^{\mathrm{e}}$ siècle ?

6 Pendant les premières années de leur présence à Vézelay, les Frères mineurs utilisèrent pour leurs offices la chapelle Sainte-Croix, qui leur avait été concédée par les moines de La Madeleine. L'usage de la chapelle et des bâtiments du prieuré Saint-Fiacre leur fut contesté par l'abbé Guichard, élu en 1230. Un conflit de plusieurs années s'en suivit, s'achevant par un concordat conclu en 1234, qui confirmait aux Franciscains la possession des lieux. Conservant l'ancienne chapelle romane, les Frères mineurs entreprirent peu après la construction d'une église conventuelle plus grande. La première pierre en fut posée vers 1240 et, en 1248, saint Louis, en visite au couvent, pouvait prier dans une église totalement achevée.

7 Cet édifice était-il celui indiqué sur les plans du XVIII siècle ${ }^{4}$ ? C'est peu probable car l'église des Cordeliers connut de nombreuses vicissitudes au cours des temps. Incendiée en 1390 et en 1481, elle fut réparée à la fin du XV ${ }^{\text {e }}$ siècle et une nouvelle consécration fut célébrée le 9 octobre 1491 par l'évêque de Bethléem. En 1568, le couvent fut de nouveau détruit lors des guerres de religion, après que les religieux aient été décapités, puis les bâtiments furent restaurés au cours du XVII siècle, de 1623 à 1670. Les travaux avaient certainement porté sur l'église, mais il semble qu'elle s'écroula en 1722 . De nouveau réparée dans les années suivantes, elle était cependant à l'abandon lorsque survint la Révolution car, en 1787, le seul Cordelier résidant à La Cordelle avait vendu les tuiles de la chapelle, puis les bois de la charpente quelques temps après.

Malgré les destructions multiples, il est possible que la chapelle de la Cordelle ait toujours été rebâtie sur ses fondations d'origine et que l'enclos contemporain reproduise le plan de la première église du XIII ${ }^{e}$ siècle ${ }^{5}$. En effet, la situation actuelle peut être rapprochée de la description des lieux donnée par le chroniqueur franciscain Salimbene de Adam en $1248^{6}$. Ce religieux, témoin de la visite du roi à La Cordelle, indique en effet que Saint Louis salua le maître-autel et que son frère Charles "faisait de nombreuses génuflexions à l'autel qui était dans le bas-côté de l'église près de l'entrée". On pourrait reconnaître dans cette brève évocation l'église principale, avec son unique 
autel dans le chevet à trois pans, et la chapelle Sainte-Croix servant de bas-côté. Notons encore que Salimbene insiste sur le caractère de grande pauvreté de la chapelle, précisant que "le roi s'assit à terre, dans la poussière (...) car l'église n'était pas pavée"'.

9 L'église des Franciscains de Vézelay et plus généralement l'ensemble du site de La Cordelle mériteraient une étude archéologique approfondie. Malgré les remaniements et les destructions, l'enclos des Cordeliers marque l'emplacement de l'une des plus anciennes fondations des Frères mineurs et son étude serait susceptible d'apporter de précieuses informations sur les premières constructions de l'ordre en France.

\section{NOTES}

1. A. NEGREL et D. VORREUX, Histoire de la Cordelle. Vézelay, polycopié, s.l., s.d [1978 ?].

2. M. QUANTIN, Répertoire archéologique du département de l'Yonne, Paris, 1868, col. 119.

3. V. PETIT, Description des villes et campagnes du département de l'Yonne, Arrondissement d'Avallon, Auxerre, 1870, p. 275.

4. 4. V. PETIT, op. cit., p. 278. D’après NEGREL et VORREUX, op. cit., p. 48, ce plan daterait de 1707.

5. 5. D. CAILlEAUX, "Les constructions médiévales des Franciscains en Bourgogne du Nord et en Champagne méridionale", dans Mémoire de Champagne, tome III, Langres, 2000, p. 268-289.

6. 6. Extraits de la chronique de SALIMBENE DE ADAM traduits et publiés dans M.-Th. LAUREILHE, Sur les routes d'Europe au XIII e siècle, Paris, 1959.

7. 7. Sur les routes d'Europe, op. cit., p. 180.

INDEX

Index géographique : France/Vézelay

Mots-clés : église franciscaine, La Cordelle de Vézelay 